\title{
Screening and Identification of Cellulase Producing Yeast from Rongkho Forest, Ubon Ratchathani University
}

\author{
Jantaporn Thongekkaew ", Jarupan Kongsanthia \\ Department of Biological Science, Faculty of Science, Ubon Ratchathani University, Thailand
}

Copyright $\mathrm{C} 2016$ by authors, all rights reserved. Authors agree that this article remains permanently open access under the terms of the Creative Commons Attribution License 4.0 international License

\begin{abstract}
In this present study, a total of 82 yeast strains were obtained from 111 samples collected from various sources such as soil, tree barks and insect frass from RongKho forest, Ubon Ratchathani University. They were screened and identified for cellulase production. Based on their capabilities of degrading carboxymethyl cellulose as a sole carbon source in solid medium, 45 strains performed cellulose hydrolysis which was verified by the colorless halo in the solid medium. Among them, 3 strains namely UBU-SK6, UBU-JK8 and UBU-JK9/1 showed higher levels of enzyme activity. After the step of solid medium selection, yeast cells were grown in liquid medium containing $1 \%$ yeast extract and different concentration of carboxymethyl cellulose (0.5-1.5\%) under shaking with 150 $\mathrm{rpm}$ at $30^{\circ} \mathrm{C}$ and for $168 \mathrm{~h}$. The enzyme activity of these 3 strains exhibited $0.224,0.238$ and $0.26 \mathrm{UmL}^{-1}$, respectively. Afterwards, these wild yeast strains were molecularly identified by sequencing the ITS1-5.8S-ITS2 and D1/D2 domains of the subunit $(26 \mathrm{~S})$ ribosomal DNA. The identification of UBU-SK6, UBU-JK8 and UBU-JK9/1 showed $98-100 \%$ similarity as Candida sp. 05-7-186T, Candida easanensis and Candida sp. ST-390 respectively.
\end{abstract}

Keywords Cellulase Producing Yeast, Candida Sp., Cellulose Hydrolysis

\section{Introduction}

Cellulolytic microorganisms play an important role in the biosphere by reducing cellulose. During their growth on cellulosic material, cellulases are synthesized by microorganisms. Cellulases from microorganisms have attracted a great deal of attention because they are highly specific biocatalysts that act in synergy to release sugars, especially glucose which is of great industrial interest due to the potential for its conversion, for example, in the textile and paper industries and in animal feed [1-3] as well as the production of bioenergy as bioethanol and biofuels [4].

There is a wide variety of microorganisms in nature which produce cellulases; only a few yeast strains have been seen as major producers of this enzyme. For this reason, explorations of biodiversity in the search for new biocatalysts by selecting microorganisms from nature represents a method for discovering new enzymes which may permit the development of bio-catalyst at an industrial scale. Currently, there is a great interest in finding microorganism species that are not yet known as interesting producers of inputs to industry. Moreover, biocatalysts also benefit in biotechnological processes which can replace many chemical processes, in terms of production of key products. As an example is the replacement of acid hydrolysis for enzymatic hydrolysis, as is well known in the industry [5].

Traditionally, yeasts have been identified and classified by cellular morphology and their distinctive reactions on a standardized set of fermentation and assimilation tests. These methods are laborious and time-consuming. Moreover, these characteristics are influenced by culture conditions and can provide uncertain results because of strain variability. Given these difficulties and the impracticality of identification most species from genetic crosses, molecular techniques, including the sequencing of rRNA genes and/or their flanking ITS regions are increasingly used for identification because the sequencing of rRNA genes and/or their flanking ITS regions have shown that many of these genptypic characteristics are strain specific for recognition of either species or genera. Moreover, these techniques are fast, easy and reasonably precise, and thus suitable for the rapid screening of isolates [6]. The main goals of the present study included the screening and identification of cellulase producing wild yeasts, isolated from samples collected from RongKho forest, Ubon Ratchathani University.

\section{Materials and Methods}

\subsection{Yeast Isolation}

Two grams of each sample from natural sources such as soil, mushroom, fruits (one wound per fruit) and insect frass was incubated in $5 \mathrm{ml}$ of Yeast extract-Malt extract (YM) 
broth $\left(3 \mathrm{gL}^{-1}\right.$ yeast extract, $3 \mathrm{gL}^{-1}$ malt extract, $5 \mathrm{gL}^{-1}$ peptone and $10 \mathrm{gL}-1$ glucose) containing $0.1 \mathrm{gL}^{-1}$ chloramphenicol and $2 \mathrm{gL}^{-1}$ sodium propionate to suppress bacterial and mold growth, respectively at $30^{\circ} \mathrm{C}$ for $2-3$ days. An aliquot of 0.1 $\mathrm{ml}$ of each yeast sample suspension was spread on YM agar supplemented with $0.1 \mathrm{gL}^{-1}$ chloramphenicol and $2 \mathrm{gL}^{-1}$ sodium propionate. Plates were incubated at $30^{\circ} \mathrm{C}$ for $2-3$ days. Colonies of yeasts were purified by repeated streaking three times on YM agar plates without the chloramphenicol and sodium propionate.

\subsection{Solid Medium Selection}

For qualitative analysis of cellulase production; all strains of yeast were incubated at $30^{\circ} \mathrm{C}$ for 2 days on carboxymethyl cellulose sodium salt (CMC-Na salt) agar (1\%yeast extract, $0.5 \%$ CMC-Na salt and $1.8 \%$ agar). After incubation, cellulase-producing strains were identified based on the formation of a clear halo around the colonies, which were made visible by Congo red staining [6].

\subsection{Index of Enzymatic Activity}

The enzymatic activities were estimated according to the method reported by Anagnostakis and Hankin [7] who proposed an Enzymatic Activity Index (EAI), which is the ratio between the halo diameter and the colony diameter.

\subsection{Determination of Carboxymethyl Cellulase Production}

The carboxymethyl cellulase-positive isolates were evaluated for carboxymethyl cellulase activity by growing the culture in carboxymethyl cellulose-yeast extract medium containing $1 \%$ yeast extract containing and different concentrations of carboxymethyl cellulose (0.5-1.5\%) under shaking with $150 \mathrm{rpm}$ at $30^{\circ} \mathrm{C}$ for 7 days. Subsequently, the cells were pelleted by centrifugation, and the cell-free supernatant was used as the source of the enzyme.

Carboxymethyl cellulase activity was determined by measuring the release of reducing sugars from CMC-Na salt using the Somogyi-Nelson method [8]. Reaction mixtures contained $0.45 \mathrm{~mL}$ of $0.5 \%$ carboxymethyl-cellulose sodium salt in $50 \mathrm{mM}$ potassium phosphate buffer, $\mathrm{pH} 7$ and $0.05 \mathrm{ml}$ of each enzyme fraction. Control lacked the enzyme fraction. After incubation at $50^{\circ} \mathrm{C}$ for $15 \mathrm{~min}$, the reaction was terminated by adding $0.5 \mathrm{~mL}$ of Somogyi reagent. The mixture was vortexed, placed in a boiling-water bath for 10 $\mathrm{min}$, and cooled to room temperature. A $0.5 \mathrm{~mL}$ of Nelson reagent was added. After being vortexed, the mixture was centrifuged to remove any precipitate, and the absorbance of the supernatant was measured at $660 \mathrm{~nm}$. One international unit (IU) of enzyme activity was defined as the amount of enzyme required to release 1 micromol of glucose from CMC-Na salt in 1 minute under the assay condition.

\subsection{Molecular identification}

Pure isolated yeast cells from $3 \mathrm{~mL}$ of each 24-h culture were harvested by centrifugation and DNA extraction as described by Sambrook et al. (1989) [10]. Identification was carried out by sequencing the gene that encodes the $5.8 \mathrm{~S}$ regions of ribosomal ribonucleic acid (RNA) and the spacer regions ITS-1 and ITS-2 after PCR amplification. To do so, the universal primers ITS4 (5' TCCTCCGCTTA-TTGATATGC $\left.3^{\prime}\right)$ and ITS5 (5' GGAAGTAAAAGTCGTAACAAGG 3') were used. The D1/D2 domains of the 26S subunit were also sequenced by using the primers NL1 $\left(5^{\prime}\right.$ GCATATCAA-TAAGCGGAGGAAAAG 3') and NL4 (5' GGTCCGTGTTTCAAGACGG $3^{\prime}$ ), according to the methodology described by Kurtzman and Robnett [9]; Esteve-Zarzoso et al. [11] and Leaw et al. [12]. The PCR product was purified by using QIAquick PCR Purification Kit and analyzed with 1.5\% agarose gel electrophoresis. The PCR products were sequenced using the ITS4, ITS5, NL-1 and NL-4 primers using either Amersham Pharmacia ALF Express II or ABI 310 (capillary) automated DNA sequencer, following the manufacturer's instructions. For identification, the obtained sequences were compared with those of all known yeast species, available at the GenBank database (http://www.ncbi.nlm.nih.gov/BLAST/) [13].

\section{Results and Discussion}

\subsection{Screening of Cellulase Producing Yeast}

For screening of cellulase producing yeast, a total of 82 yeast strains were grown in Petri dishes in order to identify those able to degrade carboxymethyl cellulose (CMC). After incubation, the plates were revealed with a Congo red solution and halo formation was analyzed. The formation of a clear halo surrounding the colony indicates hydrolytic activity (Figure 1). The enzymatic activity index (EAI) is a semi-quantitative parameter commonly used to assess enzyme production by microorganisms in solid medium [7, 14]. The result of cellulase producing yeast screening showed that 45 strains performed cellulose hydrolysis (Figure 2). Figure 2 shows values of enzyme activity recorded for the 45 selected strains when grown on solid medium containing carboxymethyl cellulose as a carbon source. Some authors recommend an EAI $\geq 2.5$ for considering a microorganism as a producer of enzymes in solid medium [5, 14, 15]. Since colonies with the highest EAI are those with higher extracellular enzyme activity [15, 16 , 17]. Among them, 3 strains namely UBU-SK6, UBU-JK8 and UBU-JK9/1 exhibited the EAI 3.5, 2.67 and 3, respectively. Therefore, all three were considered as cellulase producing strains and were assayed in liquid medium fermentations. 


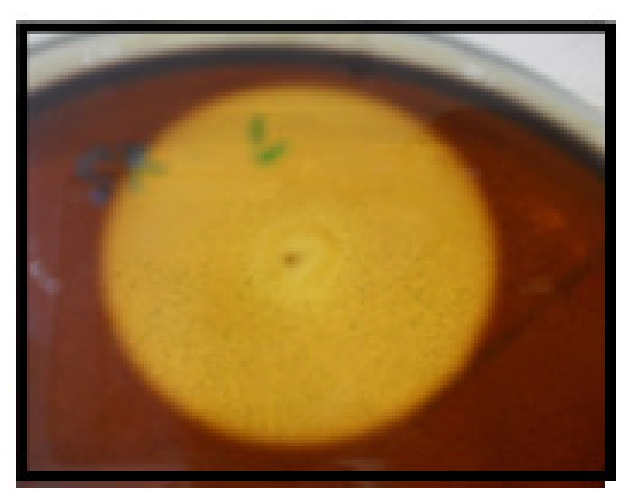

Figure 1. Halo of hydrolysis formed around the colony when grow for 48 $h$ at $30^{\circ} \mathrm{C}$

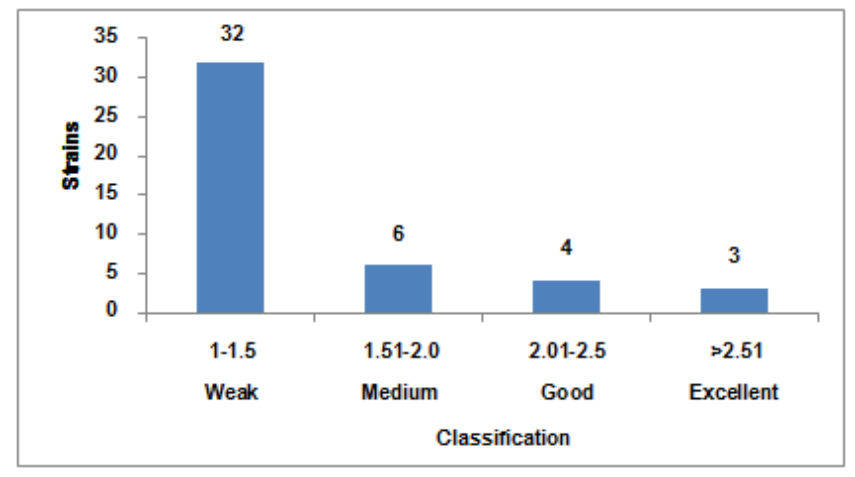

Figure 2. Classification of enzymatic activity indices (EAI) for 45 cellulase producing strains after $48 \mathrm{~h}$ at $30^{\circ} \mathrm{C}$ on $\mathrm{CMC}$ solid medium

\subsection{Production of Cellulase in Liquid Medium}

The result of cellulase production of three strains selected (UBU-SK6, UBU-JK8 and UBU-JK9/1) showed that culture medium containing $1.0 \% \mathrm{CMC}$ is the most effective induction of the enzyme production; this value is quite close to the results for cellulase production by Pseudomonas sp. [18] and Alternaria sp. MS28 [19]. The highest cellulase activity of UBU-SK6 was observed at $96 \mathrm{~h}$ of fermentation $\left(0.224 \mathrm{UmL}^{-1}\right)$ (Figure 3) while the highest enzyme activity of yeast strains UBU-JK8 and UBU-JK9/1 were observed at $120 \mathrm{~h}$ of fermentation $\left(0.238\right.$ and $0.26 \mathrm{UmL}^{-1}$, respectively) as shown in Figures 4 and 5 . When comparing cellulase production in our study to different earlier yeast strains, the activities of yeast named UBU-SK6, UBU-JK8 and UBU-JK9/1) were lower than those of Candida stellata (30.6 UmL ${ }^{-1}$ ) [20], Aureobasidium pullulans strain PJF-4b $\left(0.44 \mathrm{UmL}^{-1}\right)$, Candida glabrata strain PJS-4a $\left(0.38 \mathrm{UmL}^{-1}\right)$ and Candida litsaeae strain PJB-3 $(0.36$ $\mathrm{UmL}^{-1}$ ) [6]. However, the yields of cellulase from our yeasts isolates were two-fold higher than those of the most active Trichosporon spp. $\left(0.12\right.$ and $\left.0.14 \mathrm{UmL}^{-1}\right)[21]$.

\section{(A)}

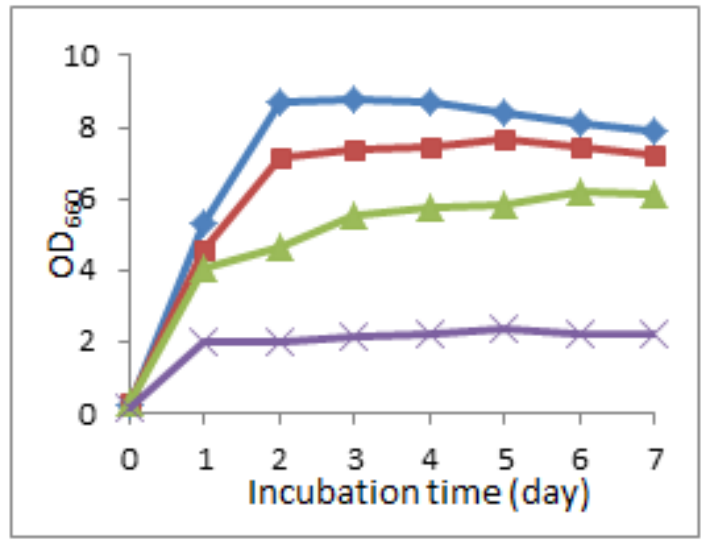

$\neg-1 \%$ Glucose
(B)

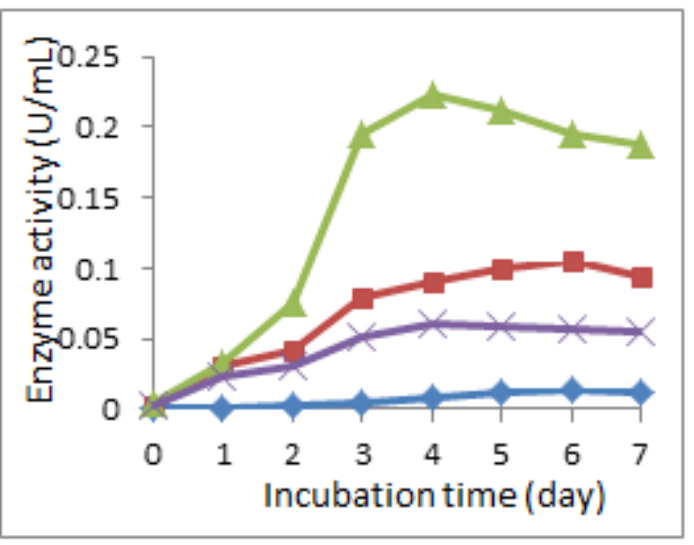

$0.5 \% \mathrm{CMC}$

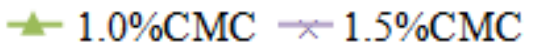

Figure 3. Effect of carboxymethyl cellulose (CMC) concentration from 0 to $1.5 \%(\mathrm{w} / \mathrm{v})$ on cellulase production of yeast named UBU-SK6. Growth (A) and enzyme production (B) were measured at $24 \mathrm{~h}$ intervals for 7 days. 
(A)

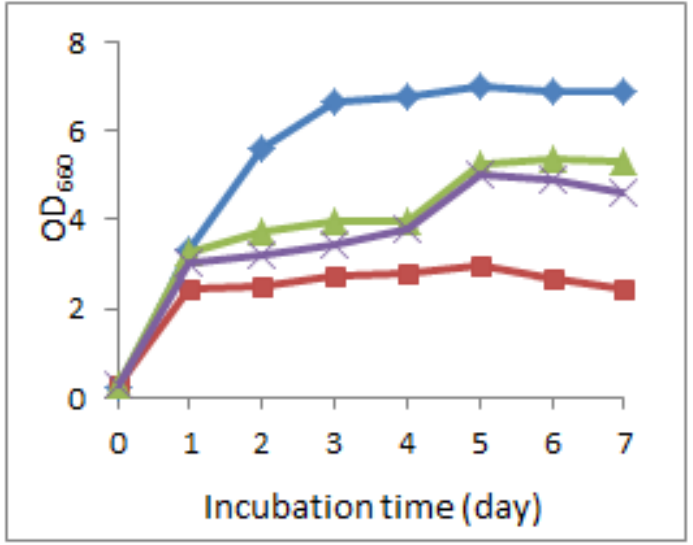

$\neg-1 \%$ Glucose $\quad \rightarrow-0.5 \% \mathrm{CMC}$
(B)

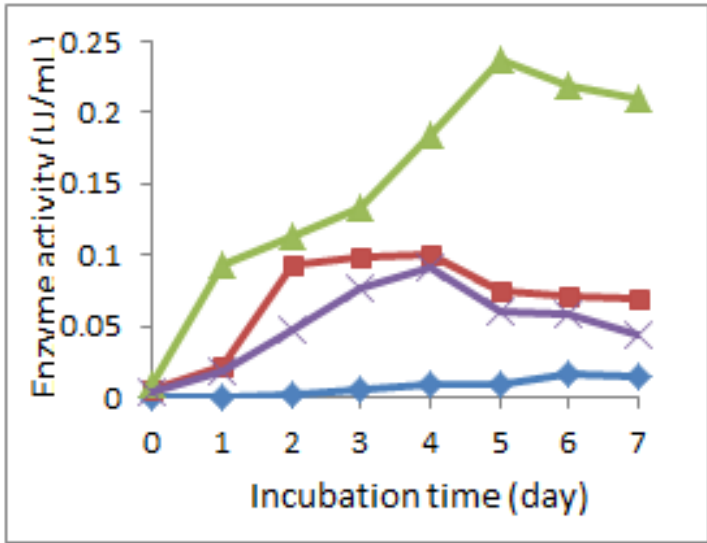

$1.0 \% \mathrm{CMC} \div 1.5 \% \mathrm{CMC}$

Figure 4. Effect of carboxymethyl cellulose (CMC) concentration from 0 to $1.5 \%$ (w/v) on cellulase production of yeast named UBU-JK8. Growth (A) and enzyme production (B) were measured at $24 \mathrm{~h}$ intervals for 7 days.

(A)

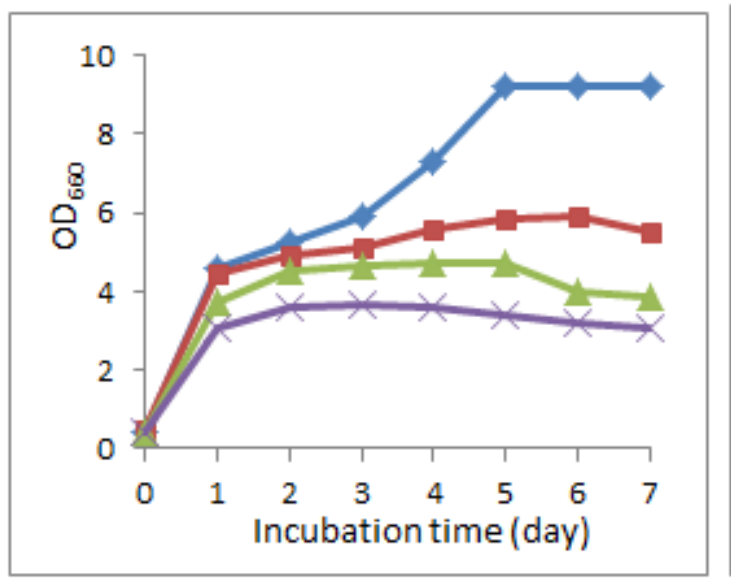

$1 \%$ Glucose

\section{$0.5 \% \mathrm{CMC}$}

(B)

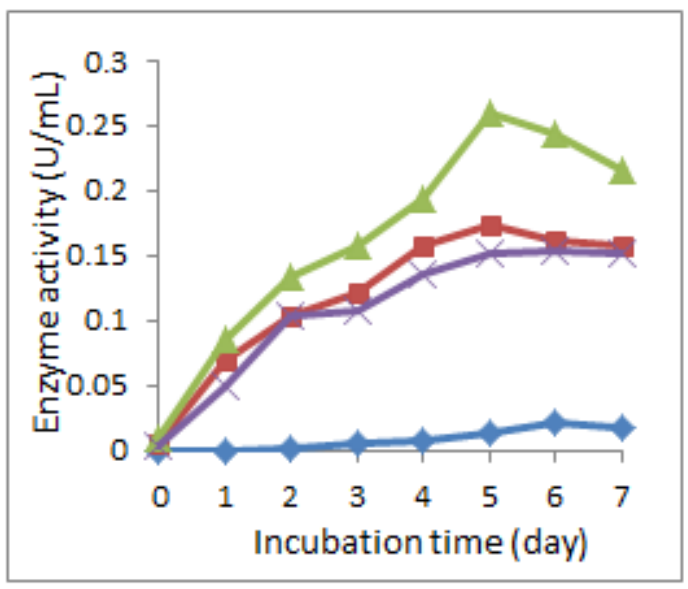

$\leftarrow 1.0 \% \mathrm{CMC} * 1.5 \% \mathrm{CMC}$

Figure 5. Effect of carboxymethyl cellulose (CMC) concentration from 0 to $1.5 \%$ (w/v) on cellulase production of yeast named UBU-JK9/1. Growth (A) and enzyme production (B) were measured at $24 \mathrm{~h}$ intervals for 7 days.

\subsection{Molecular Identification}

Molecular identification was based on ribosomal targets: the ITS1-5.8S-ITS2 and D1-D2 domains of the RNA operon. In recent years, the number of ITS sequences available in public databases has increased significantly, and the expanding database may improve the quality and accuracy of fungal identification $[11,22]$. The D1/D2 recombinant deoxy-ribonucleic acid (rDNA) region has been sequenced for almost all known yeasts, including non-pathogenic species. As an identification tool, the sequencing of this region is relatively simple to apply and yields clear results [9, 11]. The BLAST searches, even as phylogenetic analysis, are used for identification by searching public databases for the closest known sequences to the unidentified yeast [23]. A BLAST search in the NCBI database
(http://blast.ncbi.nlm.nih.gov/Blast.cgi) of the ITS1-5.8S-ITS2 and D1/D2 domains of the subunit (26S) ribosomal DNA of UBU-SK6, UBU-JK8 and UBU-JK9/1 showed $98-100 \%$ sequence identity with Candida sp. 05-7-186T, Candida easanensis and Candida sp. ST-390 respectively.

\section{Conclusions}

From a total of 82 yeast strains, 45 strains showed a halo of hydrolyzed substrate in the solid medium and three strains which were isolated from soil stood out for having high levels of enzyme activity. Considering production of cellulase from these yeast strains in liquid media, the result showed that the enzyme activity of these 3 strains, UBU-SK6, UBU-JK8 and UBU-JK9/1, exhibited 0.224, 0.238 and 0.26 
$\mathrm{UmL}^{-1}$, respectively. The identification of UBU-SK6, UBU-JK8 and UBU-JK9/1 by sequencing the ITS1-5.8S-ITS2 and D1/D2 domains of the subunit (26S) ribosomal DNA showed $98-100 \%$ similarity as Candida sp. 05-7-186T, Candida easanensis and Candida sp. ST-390 respectively. Currently, little is reported in literature regarding the production of cellulases from Candida genus. However, our study describes cellulase production from this resource can contribute to development of microbial bank and provide data on enzyme characteristics for cellulose hydrolysis into fermentable sugars which could have potential for a wide range of industries such as animal feed and biofuel production.

\section{Acknowledgements}

The authors wish to express their gratitude to Higher Education Research Promotion (HERP) belonging to office of the higher education commission for a financial support.

\section{REFERENCES}

[1] Enari, T.M. (1983). Microbial cellulases: In:Microbial enzymes and biotechnology, Foogarty, W.M. (Ed). Applied Science Publishers, London, pp. 183-224.

[2] Suchita, N. and Ramesh, C.K. (2006). Bleaching of wheat straw-rich soda pulp with xylanase from a thermoalkalophilic Streptomyces cyaneus SN32. Bioresource Technology. 97, 2291-95

[3] Zhou, J., Wang, Y., Chu, J., Zhuang, Y., Zhang, S. and Yin, P. (2008). Identification and purification of the main componentsof cellulases from a mutant strain of Trichoderma viride $\mathrm{T}$ 100-14. Bioresour. Technol., 99: 6826-6833.

[4] Castro, A.M. and Pereira, N.J. (2010). Production, Properties and Application of Cellulases in the Hydrolysis of Agroindustrial Wastes. Quim. Nova., 33(1): 181-188.

[5] Peixoto, A.B. (2006). Study of the production of enzymes and gums by wild yeasts collected in various regions of Brazil. M.S. Thesis. Faculty of Food Engineering, University of Campinas, Brazil, p. 84.

[6] Thongekkaew, J., Khumsap, A. and Chatsa-nga, P. (2012). Yeasts in mixed deciduous forest areas of Phujong Nayoy National Park and their ability to produce xylanase and carboxymethyl cellulase. Songklanakarin J. Sci. Technol. 34 (2), 157-163.

[7] Anagnostakis, S.L. and Hankin, L. (1975). Use of selective media to detect enzyme production by microorganisms in food products. J. Milk Food Technol., 38: 570-572.

[8] Somogyi, M. (1952). Notes on sugar determination. J. Bio. Chem. 195, 19-23.
[9] Kurtzman, C.P. and Robnett, C.J. (1997). Identification of clinically important ascomycetous yeasts based on nucleotide divergence in the 5' end of the large-subunit (26S) ribosomal DNA gene. J. Clin. Microbiol., 35: 1216-1223.

[10] Sambrook, J., Fritsch, E.F. and Maniatis, T. (1989). Molecular cloning: a Laboratory manual. 2nd(Ed). Cold Spring Harbor Publishers Inc, New York, USA

[11] Esteve-Zarzoso, B., Belloch, C., Uruburu, F. and, Querol, A. (1999). Identification of yeast by RFLP analysis of the 5.8S rRNA gene and the two ribosomal internal transcribed spacers. Int. J. Syst. Bacteriol., 49: 329-337.

[12] Leaw, S.N., Chang, H.C., Sun, H.F., Barton, R., Bouchara, J.P. and Chang, T.C. (2006). Identification of medically important yeast species by sequence analysis of the internal transcribed spacer regions. J. Clin. Microbiol., 44: 693-699.

[13] Yarrow, D. (1998). Methods for the isolation, maintenance and identification of yeasts. In: Kurtzman CP, Fell JW (eds) The yeasts, a taxonomic study, 4th ed. Elsevier, Amsterdam, The Netherlands.

[14] Lopes, F., Motta, F., Andrade, C.C.P., Rodrigues, M.I. and, Maugeri-Filh, F. 2011. Thermo-Stable Xylanases from Non Conventional Yeasts. J. Microbial. Biochem. Technol., 3(3): 36-42.

[15] Oliveira, N.A., Oliveira, L.A., Andrade, J.S. and Chagas Júnior, A.F. (2006). Extracellular hydrolytic enzymes in indigenous strains of rhizobia in Central Amazonia, Amazonas, Brazil. Ciênc. Tecnol. Aliment. 26: 853-860.

[16] Ceska, M. (1971). Enzyme catalysis of solidified media. Eur. J. Biochem., 71(22): 186-192.

[17] [Ruegger, M.J.S. and Tauk-Tornisielo, S.M. (2004). Cellulase activity of fungi isolated from soil of Juréia-Itatins, São Paulo, Brazil. Revista Brasil Bot., 27(2): 205-211.

[18] Gautam, S.P., Bundela, P.S., Pandey, A.K., Jamaluddin, Awasthi, M.K. and Sarsaiya, S. (2010). Cellulase production by Pseudomonas ap. Isolated from municipal solid waste compost. Int. J. Acad. Re. 2, 330-333.

[19] Sohail, M., Ahmad, A., and Khan S.A. (2011). Production of cellulases from Alternaria sp. MS28 and their partial characterization. Pak. J. Bot. 43(6), 3001-3006.

[20] Strauss, M.L.A., Jolly, N.P., Lambrechts1, M.G. and van Rensburg, P. (2001). Screening for the production of extracellular hydrolytic enzymes by non-Saccharomyces wine yeasts. J. Appl. Micro. 91, 182-190.

[21] Stevens, B.J.H. and Payne, J. 1977. Cellulase and Xylanase Production by Yeasts of the Genus Trichosporon. J. Gen. Micro. 100, 381-393.

[22] Hinrikson, H.P., Hurst, S.F., Lott, T.J., Warnock, D.W. and Morrison, C.J. (2005). Assessment of ribosomal large-subunit D1-D2, internal transcribed spacer 1, and internal transcribed spacer 2 regions as targets for molecular identification of medically important Aspergillus species. J. Clin. Microbiol., 43: 2092-2103.

[23] Suh, S.O., Blackwell, M., Kurtzman, C.P. and Lachance, M.A. (2006). Phylogenetics of Saccharomycetales, the ascomycete yeasts. Mycologia, 98(6): 1006-1017. 